\title{
LA CONSTRUCCIÓN DEL PAISAJE TURÍSTICO EN LA CIUDAD DE BUENOS AIRES Análisis sobre la participación de los actores involucrados a través de guías turísticas y comunidades de contenido
}

\author{
Luciana Rodriguez \\ CONICET- Instituto de Geografía, UBA \\ Dra. Arq. Lorena Vecslir \\ lucianarodriguez@conicet.gov.ar
}

\section{RESUMEN}

La ponencia propone una primera aproximación al paisaje turístico de la ciudad de Buenos Aires, uno de los destinos más importantes de América Latina, a partir del análisis de las acciones que los actores involucrados en su desarrollo llevan a cabo. Estas acciones, tienen por finalidad señalar los atractivos que deben visitarse dentro de la ciudad y están estrechamente ligadas al contexto de hábitos, costumbres y modas en el que se insertan, tanto sus promotores (gobierno y sector privado) como sus destinatarios (turistas y residentes). La importancia de examinarlas radica en las modificaciones simbólicas y materiales que estas selecciones suscitan en los lugares involucrados y en la forma de concebirlos. En base al estudio de guías y comunidades de contenido, se propone un posible modelo de análisis para el estudio del paisaje turístico a fin de detectar, en primera instancia, los principales rasgos morfológicos y representaciones que lo caracterizan.

Palabras clave: Paisaje Turístico, Buenos Aires, Atractivos, Actores, Guías de Turismo

\begin{abstract}
The paper proposes a first approach to the tourist landscape of the city of Buenos Aires, one of the most important destinations in Latin America, based on the analysis of the actions that the actors involved in its development carry out. These actions are intended to indicate the attractions that must be visited within the city and are closely linked to the context of habits, customs and fashions in which both the promoters (government and the private sector) and their target groups (tourists and residents) ). The importance of examining them lies in the symbolic and material changes that these selections raise in the places involved and in the way they are conceived. Based on the study of guides and content communities, a possible analysis model for the study of the tourist landscape is proposed in order to detect, in the first instance, the main morphological features and representations that characterize it.
\end{abstract}

Keywords: Touristscape, Buenos Aires, Attractions, Actors, Tourist Guides 


\section{INTRODUCCIÓN}

Durante los últimos 60 años la actividad turística se ha incrementado de manera descomunal. ${ }^{1}$ Según cifras recientes provistas por la Organización Mundial del Turismo (OMT) las llegadas de turistas internacionales a escala mundial han pasado de 25 millones en 1950 a 1.186 millones en 2015, siendo el $53 \%$ de las mismas por motivos de vacaciones, esparcimiento u otras formas de ocio. Esto ha convertido al turismo en una de las ramas económicas más importantes del mundo, representando el 7\% las exportaciones mundiales de bienes y servicios y ocupando el tercer puesto como categoría mundial de exportación (Organización Mundial del Turismo, 2017). De acuerdo a una proyección que la misma organización realizó, se prevé que las llegadas de turistas internacionales crezcan un 3,3\% al año entre 2010 y 2030, lo que implicaría alcanzar los 1.800 millones de turistas en 2030. Al mismo tiempo, se estima que las llegadas en destinos emergentes crecerán al doble que aquellas en economías avanzadas, representando 1.000 millones de llegadas internacionales para 2030 (Organización Mundial del Turismo, 2011).

Este panorama de crecimiento continuo plantea la necesidad de indagar sobre las lógicas e intereses que subyacen a la actividad turística, tanto para generar herramientas que permitan aprovechar los beneficios económicos que comporta su desarrollo, como para anticiparnos a las problemáticas derivadas de su masividad, principalmente aquellas relacionadas con la identidad social y espacial de los lugares receptores.

La ponencia propone una primera aproximación al paisaje turístico de la ciudad de Buenos Aires, uno de los destinos más importantes de América Latina, a partir del análisis de las acciones que los actores involucrados en su desarrollo llevan a cabo. Estas acciones, en muchos casos, implican señalar los atractivos que deben visitarse dentro de la ciudad y están estrechamente ligadas al contexto de hábitos, costumbres y modas en el que se insertan, tanto sus promotores (gobierno y sector privado) como sus destinatarios (turistas y residentes). La importancia de examinarlas radica en las modificaciones simbólicas y materiales que estas selecciones suscitan en los lugares involucrados y en la forma de concebirlos. Sobre este tema el trabajo discutirá la influencia de los procesos de homogeneización cultural, característicos de la era post-moderna, en la construcción de la atractividad turística y en la definición de los rasgos que la han caracterizado tradicionalmente: la diferenciación y la autenticidad. Derivados de estos procesos, se discute sobre la incorporación de nuevas ciudades a los repertorios turísticos y en la influencia que la Web 2.0, a través de las críticas y comentarios en las redes sociales, puede tener en sus representaciones.

Para comprender cómo se desarrollan estas dinámicas en Buenos Aires, se realizará un análisis en base a guías turísticas impresas y on-line del año 2016, fundado en dos motivos principales. Por un lado, el par indisociable que históricamente han formado con la actividad turística, evidenciando las selecciones -aquello "que debe ser visto"- que sus creadores hacen de la ciudad. Por otro, el uso extendido que poseen entre los diferentes grupos de actores "modeladores" del paisaje turístico: sector público (gobierno nacional y local), sector privado (empresas de diversa índole y las asociaciones que las respaldan) y destinatarios (turistas, habitantes locales). Para analizar las preferencias de estos últimos, el estudio se orientará en las guías online producidas por comunidades de contenido, debido a la participación masiva de la audiencia en su producción, lo que está cambiando el rol que habitantes locales y turistas tienen en la construcción del paisaje turístico.

A través de la comparación de las selecciones manifestadas por los distintos grupos de actores, se espera poner en evidencia algunas de las lógicas e intereses que subyacen a sus acciones y, principalmente, los rasgos morfológicos y representaciones que las caracterizan, para determinar cómo es el paisaje turístico que se está construyendo en la ciudad de Buenos Aires.

\section{EL PAISAJE TURÍSTICO DE LA CIUDAD}

Aunque el significado de "paisaje" es recreado constantemente, existen dos conceptos mayormente difundidos en el campo de la geografía: el de paisaje como una forma pictórica de mirar el mundo ${ }^{2}$ y el de paisaje como porción material de entorno natural o cultural (Duncan, 1995). En este trabajo, se retoman ambas

\footnotetext{
${ }^{1}$ De acuerdo a la Organización Mundial del Turismo, el turismo "es un fenómeno social, cultural y económico relacionado con el movimiento de las personas a lugares que se encuentran fuera de su lugar de residencia habitual por motivos personales o de negocios/profesionales. Estas personas se denominan visitantes (que pueden ser turistas o excursionistas; residentes o no residentes) y el turismo tiene que ver con sus actividades, de las cuales algunas implican un gasto turístico." (http://media.unwto.org/es/content/entender-el-turismo-glosario-basico)

${ }^{2}$ Ver Cosgrove (1985) para una explicación detallada sobre esta idea.
} 
ideas desde la perspectiva desarrollada por Soper, Greer, Metro-Roland, \& Knudsen (2008), entendiendo al paisaje no sólo como como un lugar sino también como la forma de concebirlo, como un hecho activo y siempre cambiante, manipulado por cada sociedad para representar sus ideas e identidad, lo que termina por generar un palimpsesto ${ }^{3}$ de paisajes superpuestos en el tiempo. Desde esta perspectiva, el paisaje es el soporte material pero también inmaterial, en el que la sociedad se representa, al tiempo que es incidida por ese mismo paisaje. La incorporación de la componente turística a la definición previa, más que un agregado, supone un tamiz, un filtro, a través del cual se interpretan las transformaciones simbólicas y materiales que sufren las ciudades en pos de intereses turísticos.

Por su parte, la valoración de la ciudad como destino turístico, no sólo se define a través del desarrollo de actividad turística en el contexto de una ciudad sino que, de acuerdo con Judd (2003), su desarrollo recién tendrá lugar a partir de la demarcación de los sitios y vistas que dentro de ella debían visitarse. Esta demarcación tuvo su origen en el siglo XX, conjuntamente con el surgimiento del turismo de masas, a través de la proliferación de guías y paquetes turísticos que señalaban todo lo que "debía ser visto" de lo que "podía ser visto", en este sentido "Todo es potencialmente una atracción. Simplemente espera que una persona se tome la molestia de señalarlo a otros como algo digno de ser mencionado o de ser visto" (MacCannell, 1999, pág. 192). De este modo, la ciudad-destino turístico se compone de elementos de la ciudad empírica seleccionados ex profeso, lo que en muchos casos ha dado lugar a transformaciones espaciales tanto para generar atributos para el consumo turístico, como para adaptar su infraestructura posibilitando la permanencia de los turistas (Ramirez, 2008).

La selección de lo que "debe ser visto" depende de quién seleccione y bajo qué propósitos pero, en líneas generales, está orientada a destacar atractivos dentro de un contexto dado. En este sentido, la noción de "atractividad" ha sido debatida tradicionalmente desde dos perspectivas: aquella que la considera como una cualidad intrínseca del lugar, preexistente a la valoración turística, y aquella que además la asocia indefectiblemente a un proceso socio-cultural que la transforma en atractivo (Ramírez, 2012), siendo este proceso producto del contexto, tanto de los actores locales como de los visitantes. En este sentido, Urry (1990) explica que los lugares con los que se encuentra el turista estuvieron previamente organizados para ser mirados y que la "mirada turística" 4 es una construcción cultural, ya que actúa como filtro de acuerdo a las experiencias, deseos, idiosincrasia, género, edad, etc., de cada persona; al tiempo que está determinada por los textos e imágenes de los lugares que se visitan. De este modo, lo que "debe ser visto" se construye como una relación dialéctica entre los actores que promocionan atractivos (gobiernos o actores privados) y los que consumen esos atractivos (turistas y residentes). ${ }^{5}$

Existen a su vez dos rasgos importantes que tradicionalmente han caracterizado a la atractividad. Por un lado, lo atractivo como diferente, es decir opuesto al contexto habitual o cotidiano y, por el otro, lo atractivoauténtico en referencia a su carácter legítimo u original. ${ }^{6}$ Sin embargo, como sostiene Cohen (2005), en la ciudad postmoderna los procesos de homogenización e hibridación cultural están reduciendo el atractivo del viaje de placer, es decir, el encuentro con lo diferente y lo auténtico, lo que tendría su respuesta en la búsqueda de una diferenciación más extrema y en la fantasía, o bien, en el cese de su búsqueda. ${ }^{7}$ Esta teoría fue desarrollada previamente por Baudrillard (1993), manifestando que los medios de comunicación masivos sustituyen lo real por copias exactas, generando hiperrealidades, lo que supone que la vida en las ciudades está exenta de experiencias auténticas debido a la creciente artificialidad creada por la industria del ocio y la entretención. Bajo esta perspectiva, la conversión de los lugares en destinos turísticos conllevaría a un proceso de estandarización espacial y cultural, la denominada "disneylización" de las ciudades (García Vázquez, 2008).

\footnotetext{
${ }^{3}$ Para un desarrollo más exhaustivo sobre la noción de palimpsesto en el territorio ver Corboz (2004).

${ }^{4}$ En inglés se utiliza el término tourist gaze, que a diferencia de look o glance, hace referencia a una mirada intencionada.

${ }^{5}$ La idea de que turistas y residentes consumen o asisten a los mismos atractivos, se fundamenta en la idea de que: "Es cada vez más difícil distinguir a los espacios para los visitantes de aquellos espacios "locales", dado que los sectores de ocio, entretención y cultura son considerados como cruciales tanto por residentes locales como por visitantes forasteros. Cuando no están viajando, los residentes locales se involucran en actividades indistinguibles de lo que hacen los turistas: salir a comer, ir al mall, caminar por la costanera, asistir a un concierto." (Judd, 2003, pág. 58).

6 "Esta forma de comprender la autenticidad de los objetos vinculada a la práctica turística ha sido cuestionada desde diferentes perspectivas. Entre ellas se destacan aquellas que asumen que la autenticidad es socialmente construida y aquellas otras que corren el foco de atención de la autenticidad de los objetos hacia la autenticidad de la experiencia turística" (Troncoso, 2013, pág. 168).

${ }^{7}$ Cohen (2005) caracteriza tres tipos de turistas postmodernos: el turista extremo, que plantea sus viajes en los márgenes más inhóspitos del sistema turístico con el objetivo de conseguir experiencias extraordinarias pero auténticas; el turista de fantasía, que encuentra en los grandes parques temáticos rasgos de hiperrealidad como respuesta a la homogeneización del mundo; y el post-turista, que no profundiza en el origen de las atracciones, prefiriendo lo sucedáneo a lo auténtico si es más cómodo o lindo y viaja en búsqueda de experiencias distintivas pero familiares.
} 
Sin embargo, esta postura es contestada por aquellas que sostienen que la búsqueda de experiencias únicas por parte de los visitantes, hace que huyan de los ambientes "armados" para ellos y, por lo tanto, resulta improbable la tendencia a la homogeneización de los destinos turísticos. Esta teoría puede asociarse al surgimiento de la "cultura-creativa", un colectivo ciudadano que asocia los lugares realistas con energías positivas, demandando autenticidad en las experiencias y prefiriendo ser ellos mismos los creadores de estas, por lo que rechazan las experiencias estandarizadas (Florida, 2002). A su vez, Judd (2003) indica que "dado que muchos residentes y visitantes buscan aquello que es único, y numerosos visitantes viajan con propósitos diferentes al turismo, la tendencia hacia la homogeneidad no es inevitable, y puede ser incluso improbable".

Bertoncello y Troncoso (2014) debaten en este sentido, sobre la incorporación de nuevas ciudades al repertorio turístico, sitios que "sin contar con condiciones excepcionales", se han transformado en destinos turísticos ofreciendo atractivos que, aunque propios, comparten características comunes a otras ciudades. Los autores centran la explicación del fenómeno en los cambios de la práctica turística, especialmente los referidos a la diversificación de usuarios y prácticas, en el marco de las modificaciones suscitadas en los centros urbanos. Este último aspecto, es explicado por Lacarrieu (2013), a través del gran desarrollo de proyectos de recualificación urbana en América Latina a partir de la década del 90, orientados a resolver los problemas socio-económicos derivados de la desindustrialización, en los que el uso de la cultura, el diseño y la estética son sus rasgos claves. Dentro de esta dinámica, la exacerbación de rasgos identitarios particulares, es utilizada como medio para atraer capitales a partir de su promoción (Mattos, 2010) siendo esto un recurso para la competencia entre ciudades que desean insertarse en las dinámicas económicas internacionales. La crítica a este tipo de acciones radica en que, a pesar de su éxito económico, pueden conducir a la teatralización de los escenarios urbanos, es decir, a la representación de espacios bajo pautas de autenticidad, pero con la introducción de un reordenamiento estético nuevo (García Vázquez, 2008). Lo cierto es que, aunque los escenarios urbanos no alcancen tal grado de "teatralización", sus transformaciones en relación al turismo parecen inevitables, ya que su propia penetración en las ciudades genera, al menos, cambios en la manera de concebirlas y en sus dinámicas cotidianas.

Asimismo, un aspecto aun no mencionado, pero que sin dudas ha influido en la introducción de nuevas ciudades al repertorio turístico, ha sido el desarrollo de la Web 2.0 y con ella, las críticas y opiniones de internet. El término, comenzó a utilizarse en el año 2004 para describir la forma en que desarrolladores de software y usuarios finales comenzaron a usar la World Wide Web, una plataforma en la que el contenido y las aplicaciones eran modificadas constantemente por todos los usuarios de manera participativa y colaborativa (Kaplan \& Haenlein, 2010). La Web 2.0 cambió en gran medida el modo en que las personas se relacionan entre sí y la forma en que consumen productos y servicios. Facebook, Twiter, Blogs, Wikipedia, YouTube, etc.; las redes sociales ${ }^{8}$ determinaron una nueva tendencia revolucionaria, principalmente, por la masividad de usuarios que involucran y por la forma en la que el contenido es construido, donde los usuarios producen la misma información que luego consumen, algo que diversos autores coinciden en llamar prosumición. ${ }^{9}$

Las cifras de la web TripAdvisor pueden ser un buen ejemplo de lo antes expuesto: esta plataforma de viajes, actualmente alcanza los 390 millones de usuarios únicos mensuales y 435 millones de comentarios dedicados a destinos, hoteles, restaurantes y atracciones (TripAdvisor, 2016). De acuerdo a un informe publicado por la misma web (2013), el 77\% de sus usuarios frecuentemente o siempre, buscan comentarios antes de elegir un hotel y el $50 \%$ antes de elegir un restaurante. Un artículo reciente elaborado por Zukin, Lindeman, \& Hurson (2015), estudió cómo las críticas on-line como agente para la promoción de cambios urbanos. Sobre la base del estudio de críticas a restaurantes en la web Yelp.com (sitio que publica críticas de usuarios sobre comercios y servicios), los autores explicaban que el efecto acumulativo de leer comentarios organizados geográficamente intensifica o contradice percepciones preexistentes de barrios, como "buenos" o "malos". Así las criticas on-line y las descripciones de los barrios contenidas en esas críticas, redibujan los mapas cognitivos de los consumidores.

Dentro de este marco y tal como mencionábamos anteriormente, son los contextos particulares de los actores involucrados en las selecciones y consumos de atractivos los que determinan sus intereses, por lo que a partir

\footnotetext{
${ }^{8}$ El término en su idioma original (inglés) es Social Media, sin embargo el uso extendido de la expresión "redes sociales" para referirnos a las aplicaciones de creación de contenido, lo hace apropiado para su traducción. De acuerdo a la clasificación de Kaplan y Haenlein (2010), pertenecen a las redes sociales: blogs, redes sociales (por ejemplo Facebook), mundos virtuales, proyectos colaborativos, comunidades de contenido y juegos virtuales.

${ }^{9}$ En su idioma original (inglés) prosumption. Término construido a partir de la conjunción de las palabras production (producción) y consumption (consumo), significando la interrelación de ambos procesos. Dado que no se han encontrado registros de esta palabra en idioma castellano, se realizó una construcción análoga utilizando las palabras producción y consumición.
} 
del estudio del caso concreto de Buenos Aires es que proponemos aproximarnos a la comprensión de cuáles son y cómo se forman los intereses que determinan ese paisaje turístico en particular.

\section{LA CIUDAD DE BUENOS AIRES Y EL TURISMO}

La Ciudad Autónoma de Buenos Aires, capital de la República Argentina, está situada en la región centroeste del país, limitando al sur, oeste y norte con la provincia de Buenos Aires y al este con el Río de la Plata. Cuenta con casi tres millones de habitantes, aunque su aglomerado urbano, el Gran Buenos Aires, tiene cerca de trece millones; siendo la mayor área urbana del país. En relación al turismo, Buenos Aires es un destino mundialmente conocido y uno de los más visitados de América Latina. De acuerdo a la web TripAdvisor, ocupa el primer lugar en el ranking de los destinos más populares en Sudamérica y se ubica número 17 entre las 25 ciudades más elegidas por los turistas, al tiempo que es el primer destino dentro de la Argentina (Clarín.com, 2016).

La popularidad de la ciudad como destino turístico se enmarca, por un lado, en sus características intrínsecas: la combinación de elementos de la tradición local con elementos globales asociados a las ciudades modernas y cosmopolitas (Bertoncello \& Troncoso, 2014); por el otro, en el desarrollo tanto de políticas públicas (nacionales y locales) como de políticas privadas de promoción, que se valen del recurso turístico como un medio para el desarrollo económico del país. Por caso, de acuerdo a estimaciones del Ente de Turismo del Gobierno de la cuidad (2015), existen 190 mil los puestos de trabajo de asalariados privados registrados dentro de las actividades relacionadas con el turismo, es decir, algo más del 10\% del total de los puestos de trabajo relevados en la ciudad.

En este sentido, desde la esfera nacional, la ley Nacional de Turismo de 2005, considera esta actividad socioeconómica como estratégica y esencial para el desarrollo del país, resultando prioritaria dentro de las políticas de Estado, en alianza con la actividad privada. En el marco de esta ley, el Instituto de Promoción Turística (INPROTUR) desarrolla programas y estrategias de fomento del turismo receptivo internacional, a través de la promoción de la "marca país" cuyo objetivo es "difundir nacional e internacionalmente los factores diferenciales de nuestro país a partir de cuatro escenarios comunicacionales: turismo, cultura, inversiones y comercio internacional" (Instituto de Promoción Turística, 2016). El conjunto de esos factores con los que tradicionalmente se relacionó a la Argentina (fútbol, tango, asado, etc.) pretenden conjugarse con las nuevas ideas sobre el país que se quieren difundir (innovación, creatividad, identidad, solidaridad).

A su vez, se creó recientemente el Plan Federal de Turismo 2016-2019, impulsado por el Ministerio Turismo de la Nación, respaldado por las 24 provincias que conforman el Estado y la Ciudad Autónoma de Buenos Aires, con el objetivo principal de fomentar el desarrollo turístico del país, a partir de cinco lineamientos estratégicos:

- Posicionar a Argentina como principal destino turístico de la región

- Promover el crecimiento del turismo interno argentino

- Mejorar la competitividad y sustentabilidad en el sector

- Aumentar la inversión

- Promover la creación de empleo en el sector turístico

Por otro lado, uno de los referentes del sector privado en el país es la Confederación Argentina de la Mediana Empresa (CAME), que a través del programa de desarrollo de MIPYMES (micro, pequeñas y medianas empresas) se propone contribuir a mejorar la competitividad del comercio minorista y de los establecimientos de servicios, en particular los dedicados al turismo, a través de la creación de Centros Comerciales a Cielo Abierto, que fomenten la actividad comercial y turística en distintas ciudades de la Argentina. En este sentido, han desarrollado diferentes intervenciones de revitalización de centros urbanos a través de acciones de mejoramiento urbano y promoción comercial, bajo la pauta de que "(...) transformar a las ciudades en atractivas y competitivas se ha convertido en un objetivo estratégico de gobiernos, instituciones y empresas." (Confederación Argentina de la Mediana Empresa, 2016).

En la esfera local, el gobierno de la ciudad de Buenos Aires, viene desplegando desde mediados de los años 2000, una fuerte estrategia de promoción desde el Ente de Turismo de la ciudad, apoyada en el desarrollo de diversos tipos de turismo (corporativo, accesible, gastronómico, LGBT, sustentable, médico, deportivo) ${ }^{10}$ con

\footnotetext{
${ }^{10}$ Para más información sobre estas estrategias, ver la sección de noticias del Sitio Oficial de Turismo del Gobierno de la Ciudad: www.turismo.buenosaires.gob.ar
} 
una contundente apuesta a las plataformas digitales, a través de recursos como: BA planner, una herramienta on-line que permite organizar los atractivos que quieren visitarse en la ciudad, de acuerdo a los intereses del usuario, o la recientemente inaugurada "tienda de experiencias turísticas", un sitio web que reúne toda la oferta de actividades que se brindan desde el sector público y privado, al tiempo que permite conocer, por ejemplo, la calificación de las actividades en TripAdvisor o saber cuántas reservas se hicieron en los últimos días. Estas acciones parecen justificarse en el creciente flujo de opiniones que recibe la ciudad a través de los medios electrónicos lo que, según expone el Ente de Turismo, permite el diseño de políticas más efectivas, al tomar en cuenta lo que el turista señala como elemento a mejorar, a la vez que permite fortalecer aquellos atributos de la estadía que los turistas consideran valiosos (Sitio Oficial de Turismo del Gobierno de la Ciudad, 2016), lo que se traduce en un mayor número de visitantes.

Las estrategias mencionadas dan cuenta de la creciente importancia que las opiniones on-line tienen para la evaluación continua de lineamientos turísticos por parte del gobierno local. También es notoria la voluntad asociativa entre gobierno y sector privado para desarrollar políticas de fomento turístico, tanto desde la esfera nacional, como lo expresa la Ley de Turismo (2004), como desde la esfera local, reflejada en el trabajo conjunto que ambos grupos desarrollan en la "tienda de experiencias turísticas". Surgen también, algunas ideas sobre la ciudad que se quiere mostrar, reflejadas, por ejemplo, en los objetivos de la "marca país", en la pluralidad de "tipos de turismo" que fomenta el gobierno local, o desde las acciones de mejoramiento urbano que CAME lleva adelante.

\section{BUENOS AIRES EN LAS GUÍAS TURÍSTICAS Primera aproximación al paisaje turístico de la ciudad}

Con el objetivo de determinar cuáles son los atractivos que se promocionan desde las distintas esferas involucradas en la construcción del paisaje turístico (pública, privada y destinatarios), se presentan a continuación los resultados preliminares del trabajo en curso que, más que arrojar datos acabados sobre el tema objeto de estudio, se propone como un posible modelo de análisis del turismo en la ciudad de Buenos Aires.

La metodología empleada se basó en el estudio de nueve guías de turismo: Guía de Buenos Aires (2016), Bus Turístico (2016) e Itinerarios del Sitio Oficial de Turismo la Ciudad (2017), emitidas por el Gobierno de la Ciudad de Buenos Aires (GC) o avaladas por el mismo; Ciudades a Pie Buenos Aires (2016), Viajar Hoy (2015) y Buenos Aires Cultural (2016), emitidas por medios gráficos, comercios y organizaciones privadas (SP); Time Out (2016), Lonely Planet (2016) y Trip Advisor (2016) plataformas web, cuyo contenido es creado en función de la opinión de sus usuarios, de allí que sean consideradas como comunidades de contenido (CC), representando tanto a turistas como a residentes. La selección de las guías se realizó en base a una muestra aleatoria simple, con la pauta de que su autoría representara a los tres grupos de actores en cuestión.

El análisis se estructuró en base dos temas principales que apuntan a determinar, en primera instancia, los rasgos morfológicos y representaciones más inmediatas de las selecciones que cada grupo realiza: líneas argumentativas y tipo/ localización de los atractivos en la ciudad.

Por un lado, la forma en la que los atractivos son agrupados en cada una de las guías, es decir, los argumentos bajo los cuales se organizan, se trascribieron en la Tabla 1 de acuerdo a los títulos principales (argumentos) y secundarios (descripción), con los que son mencionados. Por el otro, la localización de esos atractivos en el la ciudad, permitió elaborar diferentes mapas bajo un código gráfico común (Figuras 1 y 2). Estos mapas se componen de cuatro elementos básicos:

- Puntos: representan elementos físicos específicos, como edificios, puentes, monumentos, plazas, etc.

- Manchas: simbolizan áreas de mayor extensión que el punto, cuyas características particulares las diferencian de las circundantes, pudiendo coincidir con límites municipales barriales.

- Líneas: se corresponden con ejes de circulación vehicular o peatonal, que son mencionados como un atractivo en sí mismos, o bien, dentro de un itinerario que expresamente los incluye dentro de un recorrido más basto.

- Color: según cuantas veces se mencione un atractivo (punto, línea o mancha), más saturado será el color con el que se lo representa.

Finalmente, los puntos mencionados se organizaron de acuerdo a siete categorías generales con el fin de determinar sus patrones de localización por tipo: gastronomía (restaurantes, bares, cafés, etc.), cultura (museos, salas de exposición, centros culturales, etc.), recreación (reservas ecológicas, parques, parques 
temáticos, plazas, etc.), patrimonio construido, compras (shoppings, comercio a cielo abierto, mercados, ferias, ejes comerciales, etc.), espectáculos y monumentos e infraestructuras (deportivas, viarias, de transporte, etc.). (Figura 3)

\subsection{Líneas Argumentales}

Una aproximación inicial al estudio de las guías, nos permite determinar que existen dos líneas argumentales principales, bajo las cuales se clasifican los atractivos: por localización y por categoría.

La primera los reúne según el barrio o el elemento urbano en torno al cual se localizan y, en general, es el modo de organización que prevalece para las guías del GC y SP. Este modo de organizar los atractivos, supone la concentración de elementos pertenecientes a diferentes categorías, vinculados por su proximidad, lo que permite unirlos a través de itinerarios ${ }^{11}$ de modo que, no sólo indican lo que debe ser visto, sino también la forma en la que debe recorrerse. Estas argumentaciones (San Nicolás, Monserrat, Plaza Francia o Calle Florida, por ejemplo), en muchos casos también se les suma un nombre que refleja cualidades asociadas al imaginario urbano que existe para el sector en cuestión, por caso: "Buenos Aires de los porteños" para referirse a los barrios de Barracas, Belgrano, Caballito y Flores que, como se muestra más adelante, se mencionan limitadamente en los circuitos turísticos. En otros casos, directamente se sustituye el nombre del emplazamiento por esa cualidad, por ejemplo: "Buenos Aires alternativo" en relación a las muestras de arte, teatro y danza que pueden visitarse en Palermo y Villa Crespo.

Así mismo, la cuestión temporal está directamente vinculada a este argumento. Las guías Viajar Hoy (2015) o Ciudades a Pie (2016), del SP, incluyen en sus itinerarios el tiempo de recorrido que estos implican para un usuario a pie. El Bus Turístico (2016), por su parte, tiene estipulado el horario específico en el que estará en cada parada, además del tiempo total que insumen sus dos recorridos, mientras que los Itinerarios Gobierno de la Ciudad (2017) ofrecen la posibilidad de recorrer la ciudad en 24, 48 horas o una semana, algo que se repite en otras guías del SP.

La segunda línea argumental, es la que predomina en las CC, y dispone los atractivos por categorías asociados a intereses específicos: desde experiencias, vistas o actividades (las formas más genéricas) hasta compras, museos, espectáculos, etc., resultando compleja de clasificar por la heterogeneidad de elementos que la componen. A diferencia del primero, este argumento reúne elementos dispersos en distintos sectores de la ciudad, a veces muy alejados entre sí, aunque con un nombre que los dota de cierta filiación y, por tanto, de sentido. El planteo de un itinerario en estos casos, es casi inviable debido a la distancia entre atractivos, pero también, por la contradicción que supondría a las actividades que las $\mathrm{CC}$ ofrecen, orientadas a que el turista se "mimetice" con los residentes locales, como lo sugieren, por ejemplo, las 20 actividades de Time Out Buenos Aires (2016). En este sentido, al orden de los atractivos por recorrido que supone el itinerario, las CC lo sustituyen por rankings, que ordenan los atractivos de acuerdo a lo que "merece ser visto" según la opinión y las crìticas de los propios usuarios.

\footnotetext{
${ }^{11}$ Se entiende por itinerario a la descripción escrita o gráfica del camino que debe seguirse para visitar distintos lugares de interés y, por tanto, supone la disposición de esos lugares (o atractivos) bajo un cierto orden.
} 


\begin{tabular}{|c|c|c|c|c|}
\hline & NOMBRE & ESPECIFICACIONES & ARGUMENTO & SUB- ARGUMENTO* \\
\hline \multirow{18}{*}{ 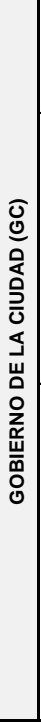 } & \multirow{2}{*}{$\begin{array}{l}\text { Bus } \\
\text { Turístico } \\
(2016)\end{array}$} & \multirow{2}{*}{$\begin{array}{c}\text { Guía impresa que muestra el recorrido del bus turístico } \\
\text { oficial de la ciudad de Buenos Aires, proponiendo dos } \\
\text { circuitos que pueden visitarse en uno o dos días } \\
\text { dependiendo del ticket que se adquiera. }\end{array}$} & Recorrido Amarillo Bus Turístico & No Aplica \\
\hline & & & Recorrido Azul Bus Turístico & No Aplica \\
\hline & \multirow{6}{*}{$\begin{array}{l}\text { Guía de } \\
\text { Buenos } \\
\text { Aires } \\
(2016)\end{array}$} & \multirow{6}{*}{$\begin{array}{l}\text { Guía impresa emitida por el Gobierno de la Ciudad, } \\
\text { cuya distribución de limita a eventos específicos, por } \\
\text { caso, la Feria Internacional de Turismo (FIT). }\end{array}$} & $\begin{array}{c}\text { BsAs Histórica: } \\
\text { San Nicolás/Monserrat }\end{array}$ & \multirow{6}{*}{ No Aplica } \\
\hline & & & $\begin{array}{c}\text { BsAs Tanguera: } \\
\text { La Boca/ San Telmo/ Balvarena }\end{array}$ & \\
\hline & & & BsAs Elegante: Recoleta/ Retiro & \\
\hline & & & BsAs Moderna: Puerto Madero & \\
\hline & & & BsAs De Autor: Palermo & \\
\hline & & & $\begin{array}{c}\text { BsAs De los Porteños: } \\
\text { Barracas/ Belgrano/ Caballito/ } \\
\text { Flores }\end{array}$ & \\
\hline & \multirow{10}{*}{$\begin{array}{l}\text { Itinerarios } \\
\text { Gobierno de } \\
\text { la Ciudad } \\
\quad(2017)\end{array}$} & \multirow{10}{*}{$\begin{array}{l}\text { Itinerarios on-line que muestra la página de Turismo del } \\
\text { Gobierno de la Ciudad, conjuntamente con "Visitas } \\
\text { Guiadas" (pagas y gratuitas), "Información Útil", } \\
\text { "Motivos para visitar Buenos Aires", etc. } \\
\text { https://turismo. buenosaires.gob.ar/es/article/bus- } \\
\text { tur\%C3\%ADstico }\end{array}$} & 24hs, 48hs o una semana & No Aplica \\
\hline & & & Recorre los barrios & $\begin{array}{c}\text { San Telmo/ Recoleta/ La Boca/ Puerto Madero/ Monserrat: Av. de Mayo/ Monserrat: Casco } \\
\text { Histórico/ San Nicolás/ Retiro/ Balvarena: Abasto/ Belgrano/ Barracas/ Palermo }\end{array}$ \\
\hline & & & Arte callejero & Ruta tradicional/ Ruta emergente \\
\hline & & & Buenos Aires alternativo & Día 1/ Día 2 \\
\hline & & & Buenos Aires multicultural & Día 1/ Día 2 \\
\hline & & & A tu presupuesto & Bajo/ Ni/ Sibarita \\
\hline & & & ¿Sólo en familia? & Buenos Aires para enamorarte/ Propuestas para adolescentes/ Actividades para niños \\
\hline & & & Bueno Aires gratis & No Aplica \\
\hline & & & Buenos Aires "gay friendly" & No Aplica \\
\hline & & & Secretos de la ciudad & Día 1/ Día 2 \\
\hline \multirow{15}{*}{ 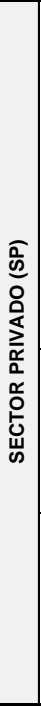 } & \multirow{11}{*}{$\begin{array}{c}\text { Viajar Hoy } \\
(2014 / 2015)\end{array}$} & \multirow{11}{*}{$\begin{array}{l}\text { Guía impresa desarrollada por la empresa de marketing } \\
\text { digital Gurú (antes Hibu), con el objetivo de publicitar } \\
\text { comercios relacionados con la industria del turismo. }\end{array}$} & Avenida de Mayo & \multirow{11}{*}{ No Aplica } \\
\hline & & & Plaza de Mayo & \\
\hline & & & Calle Florida & \\
\hline & & & Calle Corrientes y Abasto & \\
\hline & & & San Telmo & \\
\hline & & & La Boca & \\
\hline & & & Puerto Madero & \\
\hline & & & Avenida Alvear & \\
\hline & & & Plaza Francia & \\
\hline & & & Palermo & \\
\hline & & & Bosques de Palermo & \\
\hline & \multirow{2}{*}{$\begin{array}{l}\text { Ciudades } \\
\text { a Pie: } \\
\text { Buenos } \\
\text { Aires } \\
(2016)\end{array}$} & \multirow{2}{*}{\begin{tabular}{|c|} 
Guía impresa, parte de la colección de "Ciudades a \\
Pie" de National Geographic, lanzada por el diario \\
Clarín en 2016. Esta colección de guías de 12 ciudades \\
capitales del mundo, contiene itinerarios y mapas con \\
el objetivo de orientar a usuario en el recorrido a pie por \\
las mismas.
\end{tabular}} & Visitas Relámpago & $\begin{array}{l}\text { Buenos Aires en un día/ Buenos Aires en un fin de semana/ Buenos Aires para divertirse/ } \\
\text { Buenos Aires para saborear/ Buenos Aires para comprar/ Buenos Aires en un fin de } \\
\text { semana con niños/ Buenos Aires y el tango/ Buenos Aires y sus museos/ Buenos Aires y } \\
\text { el Papa Francisco }\end{array}$ \\
\hline & & & Barrios de Buenos Aires & $\begin{array}{c}\text { La Boca/ Puerto Madero/ San Telmo/ De Casa Rosada al Congreso/ Centro Porteño/ De } \\
\text { Retiro a Recoleta/ Palermo/ Belgrano y Costanera Norte }\end{array}$ \\
\hline & \multirow[t]{2}{*}{$\begin{array}{l}\text { Buenos } \\
\text { Aires } \\
\text { Cultural } \\
(2016)\end{array}$} & \multirow{2}{*}{\begin{tabular}{|c|} 
Guía on-line e impresa, desarrollada por la asociación \\
Art Noveau de Buenos Aires, con el patrocinio de la \\
Secretaria de Cultura de FECOBA y auspicio del \\
Ministerio de Cultura CABA y Ministerio de Turismo de \\
la Nación, que promociona los Centros Comerciales \\
barriales porteños y su identidad cultural. \\
http://www. aanba.com.ar/mapas-y-tours/el-gran- \\
mapa.html
\end{tabular}} & Barrios & $\begin{array}{l}\text { Villa del Parque/ Palermo Viejo/ Almagro/ Flores/ Villa Devoto/ Chacarita/ Av. Montes de } \\
\text { Oca/ Av. Callao- Av. Córdoba/ Arenales/ Santa Fe/ Av. de Mayo/ Calle Florida/ Circuito } \\
\text { Once- Congreso/ Casco Histórico- Plaza Dorrego/ Av. Entre Ríos/ Parque de los Patricios }\end{array}$ \\
\hline & & & Temas & $\begin{array}{l}\text { Circuito Merechal/ Anticuarios de San telmo y Feria/ Fileteado porteño/ Mapa del Tango/ } \\
\text { Malbec en Buenos Aires 2016/ Museos }\end{array}$ \\
\hline \multirow{19}{*}{ 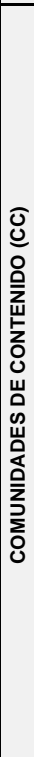 } & \multirow{8}{*}{$\begin{array}{c}\text { Lonely } \\
\text { Planet } \\
\text { Buenos } \\
\text { Aires } \\
(2016)\end{array}$} & \multirow{8}{*}{$\begin{array}{c}\text { Versión on-line de la mundialmente difundida guía } \\
\text { impresa Lonely Planet. En su web se propone un mapa } \\
\text { de la ciudad de Bunos Aires, dónde los lugares a visitar } \\
\text { se ordenan por temáticas y los ítems que ellos } \\
\text { contienen se disponen en orden decreciente a partir de } \\
\text { "lo mejor" a visitar. }{ }^{\star \star \star} \\
\text { https://mww.lonelyplanet.com/argentina/buenos-aires }\end{array}$} & Experiencias & \multirow{8}{*}{ No Aplica } \\
\hline & & & Vistas & \\
\hline & & & Restaurantes & \\
\hline & & & Actividades & \\
\hline & & & Entreteni-mientos & \\
\hline & & & Shopping & \\
\hline & & & Transporte & \\
\hline & & & Eventos & \\
\hline & & & Atracciones y lugares de interés & \\
\hline & & & Compras & \\
\hline & & & Museos & \\
\hline & & $\begin{array}{c}\text { Web de viajes que ofrece "que hacer" en Buenos Aires, } \\
\text { a través de diferentes rankigs según tipos de }\end{array}$ & Conciertos y espectáculos & \\
\hline & TripAdvisor & atracciones. . $^{\star \star \star}$ & Naturaleza y parques & No Aplica \\
\hline & (2016) & 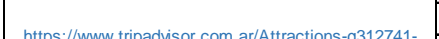 & Tours & No Aplica \\
\hline & & 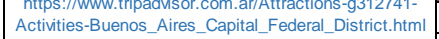 & Vida Nocturna & \\
\hline & & & Actividades al aire libre & \\
\hline & & & Clases y talleres & \\
\hline & & & Vecindario & \\
\hline & $\begin{array}{l}\text { Time Out } \\
(2016)\end{array}$ & 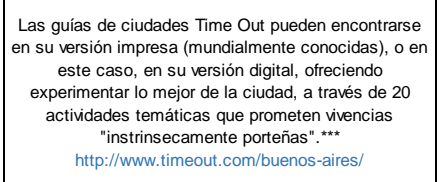 & 20 cosas para hacer en... & $\begin{array}{l}\text { Become a Boca fan/ Eat intestines and even more glands/ Frolic in a love hotel/ Tour the } \\
\text { eye of the Tigre/ Witness the social coming of Christ/ Get lost among the dead/ Dine in } \\
\text { style/ Mind your toes at a milonga/ Snack on coffee and medialuna/ Drink until the early } \\
\text { hours/ Have a picnic and go bird watching/ Marvel at South American modern masters/ D is } \\
\text { for dulce de leche/ Pay homage to Evita/ Go relic hunting on San Telmo/ Pick up classic } \\
\text { souvenirs/ See a polo match in Palermo/ Tango, tango and yet more tango!/ Groove to } \\
\text { South America's best DJs/ Turn fashion conscious in Palermo Viejo }\end{array}$ \\
\hline
\end{tabular}

* Los sub- argumentos representan otras categorías contenidas dentro de los argumentos principales. Aquí no se mencionan los puntos específicos a visitar, que podrán constatarse en los mapas. ** En el año 2017 el Bus Turístico ha modificado su programa ofreciendo un tercer recorrido.

Tabla 1. Argumentos en las guías turísticas y comunidades de contenido analizadas

Fuente: Elaboración propia a partir de los datos recogidos de guías turísticas y comunidades de contenido. 


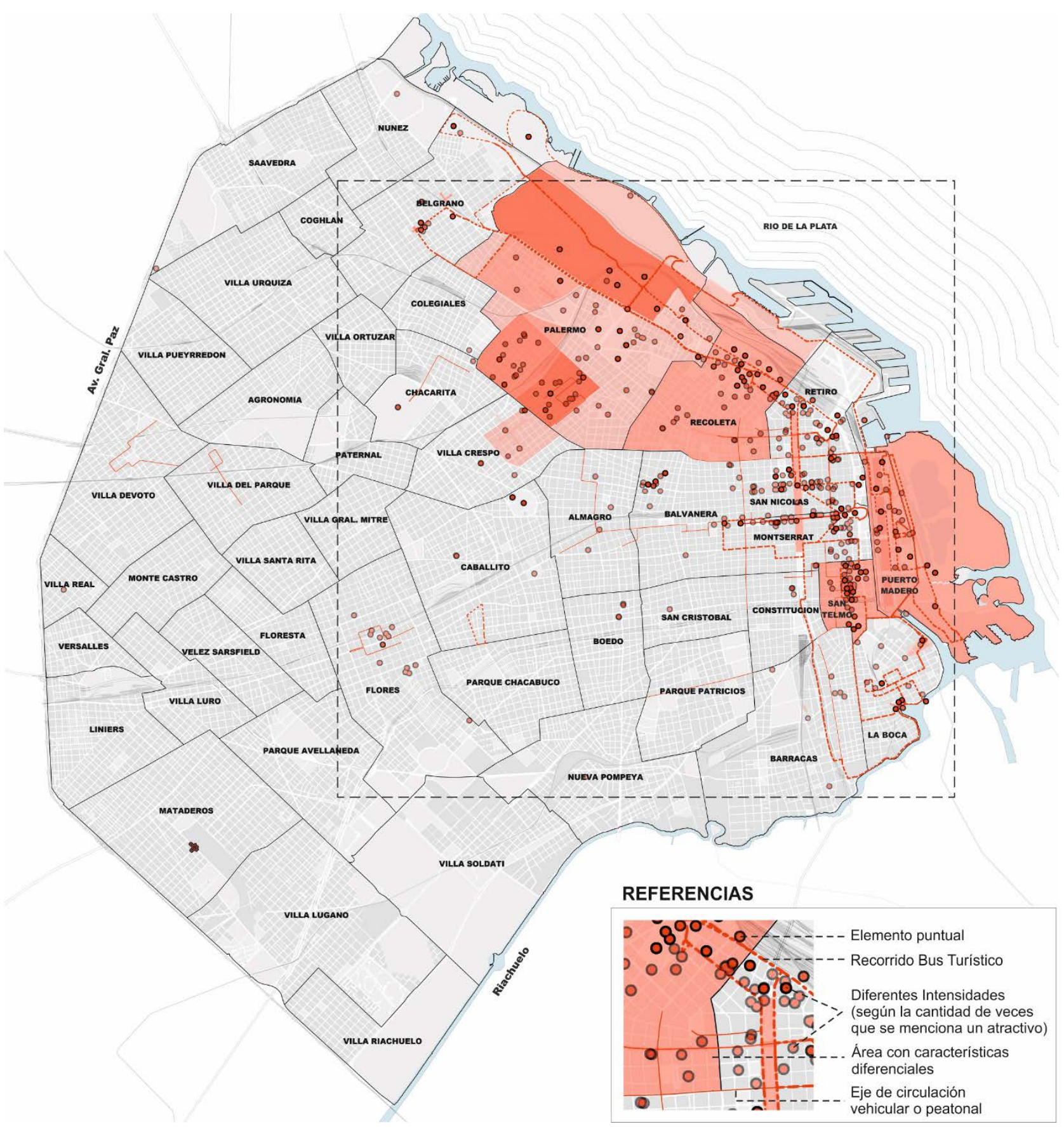

Figura 1. Lo que "debe ser visto" en la ciudad de Buenos Aires: localización espacial de los atractivos Fuente: Elaboración propia a partir de los datos recogidos de guías turísticas y comunidades de contenido. 


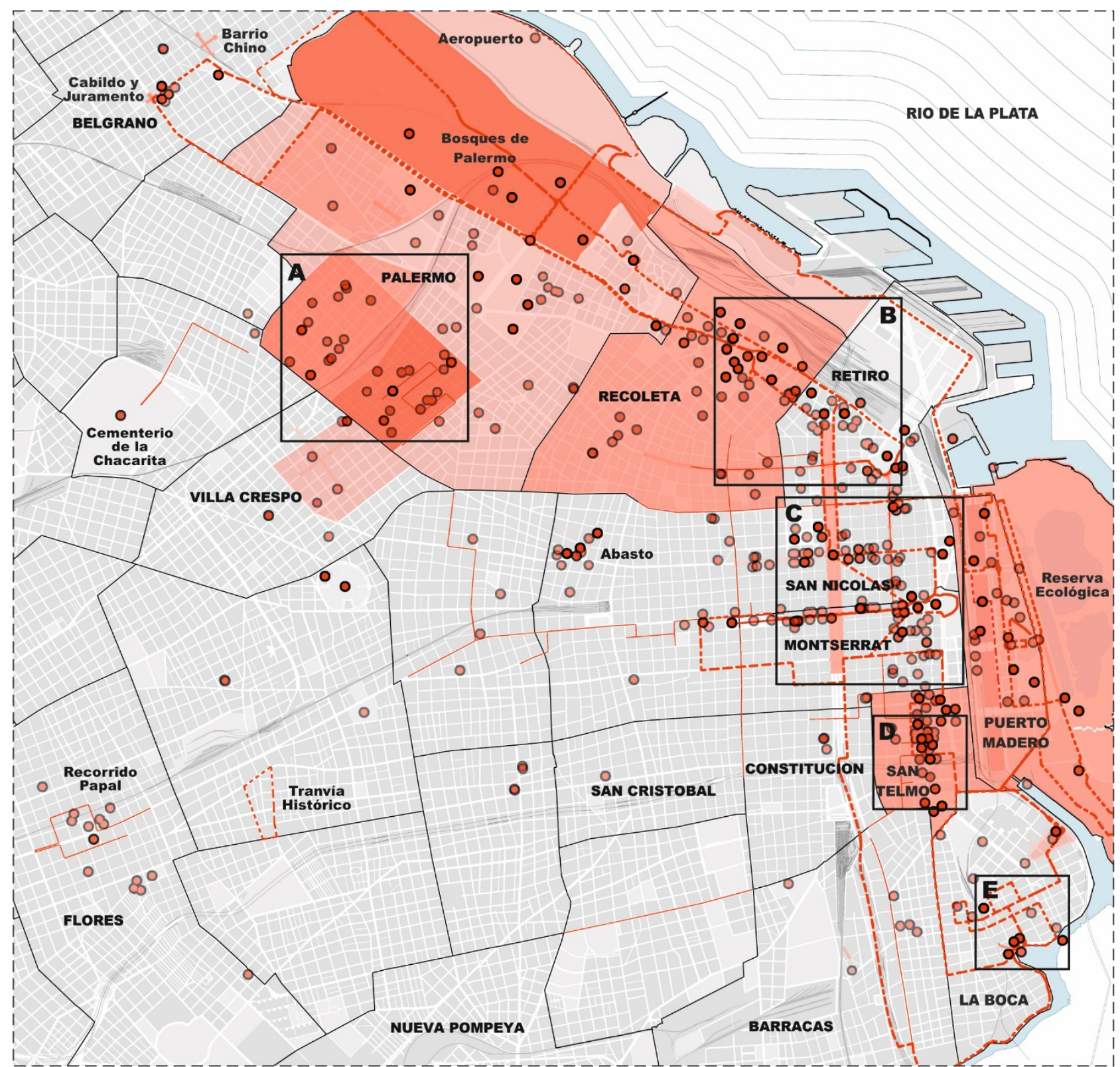

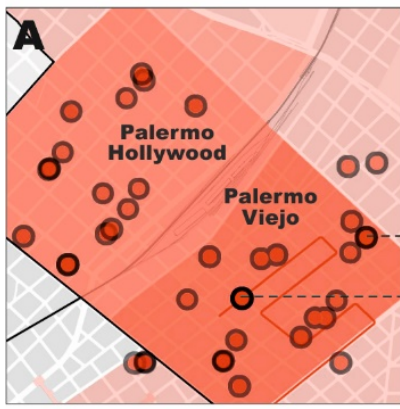

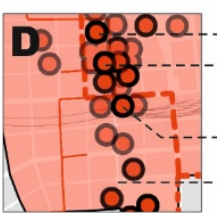

Mercado de

San Telmo

Dorrego

Museo de

Museo de

Calle

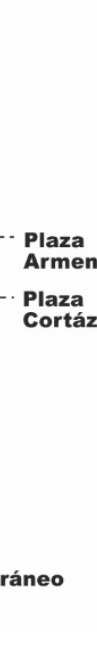

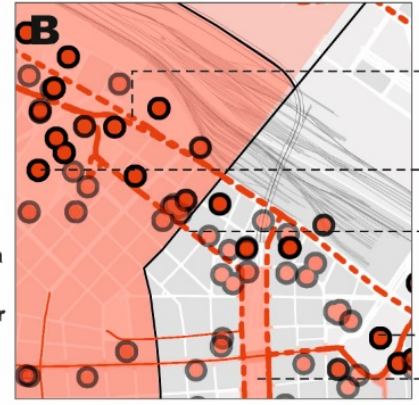
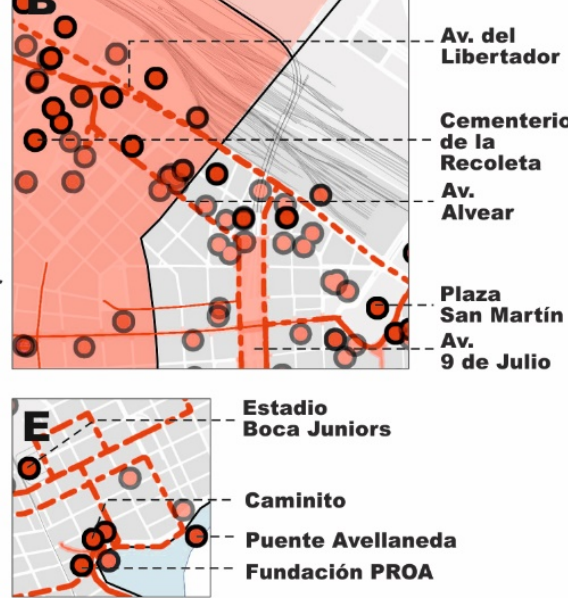

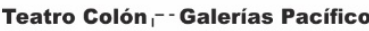

Obelisco Calle Florida

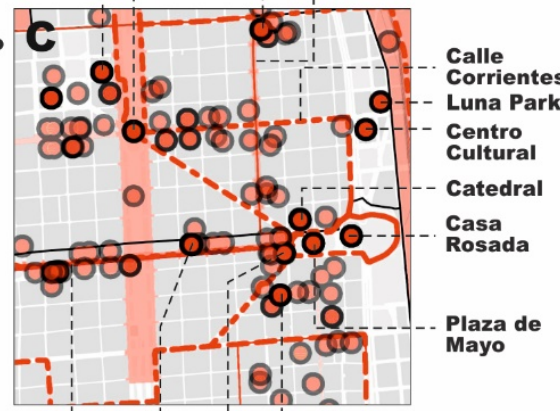

Av. de Mayo Cabildo Manzana

Café Tortoni ${ }^{\text {' }}$

Figura 2. Detalle de la Figura 1

Fuente: Elaboración propia a partir de los datos recogidos de guías turísticas y comunidades de contenido. 


\subsection{Localización de los atractivos}

Las selecciones de las guías expresadas en la Figura 1, muestran que la ciudad que se promociona para el turismo concentra el interés en sectores específicos de Buenos Aires. El mapeo de los mismos, da cuenta de una forma de mostrar la ciudad que parece apoyarse en aquella tradicional dicotomía de la "ciudad europea" encarnada por la zona de Recoleta, y la de los inmigrantes, en la zona de San Telmo y La Boca, al tiempo que acentúa la posición dominante del centro histórico.

El análisis sobre el sector del centro histórico permite ver que los puntos que lo estructuran, se ordenan en pequeños grupos dispuestos de manera sucesiva, coincidiendo con nodos, hitos o sendas importantes ${ }^{12}$ : Plaza Dorrego y Calle Defensa, Plaza de Mayo, Teatro Colón, el remate de calle Florida con Plaza San Martín, el remate de Av. 9 de Julio con Av. Del Libertador y el cementerio de Recoleta. Adicionalmente, dos grupos de puntos dispuestos en relación a Av. de Mayo y Av. Corrientes atraviesan estos conjuntos en sentido perpendicular.

Por el otro, a la ausencia de manchas en el sector del centro, se contraponen las que subyacen a los barrios de Recoleta y Palermo al norte, y a San Telmo y Puerto Madero al sur. Una hipótesis para estas diferentes representaciones, radica en la identificación y significado atribuido a cada uno de estos sectores en el imaginario colectivo. Tal como se mencionó antes, la presencia de hitos, nodos y sendas importantes en el centro de la ciudad, posibilita un mayor reconocimiento e identificación de sus partes, mientras que las características físicas que determinan los barrios son continuidades temáticas, muchas veces emparentadas a cierta homogeneidad visual, arquitectónica o de fachadas (Lynch, 1960), lo que termina por generar identificaciones en forma de regiones más que puntos.

A su vez, se distinguen tres grupos de puntos por fuera del conjunto principal, aunque contiguos, correspondiéndose con el sector de Caminito en La Boca, el Abasto en Balvarena, y el cruce de Cabildo y Juramento en el barrio de Belgrano. A estos tres se suma un cuarto, desarrollado en el barrio de Flores y, por tanto, aislado del grupo anterior: el circuito papal.

Este esquema de distribución, sin embargo, no es exactamente representativo de los tres grupos estudiados (GC, SP y CC). El desglose de los mapas por grupos (Figura 2) arroja que, con distintos énfasis, el GC y SP concentran sus itinerarios en el centro histórico y en sus áreas inmediatas (San Telmo y Recoleta). Sin embargo, el desarrollo del mapa del GC es más extenso, llegando en el sector norte hasta el Estadio de River Plate en el extremo norte del barrio de Belgrano, al tiempo que el Bus Turístico se presenta como el estructurador de los atractivos, englobando en su recorrido las zonas de puntos principales. Para el mapa del $\mathrm{SP}$, en cambio, son las calles Defensa y 9 de Julio con su prolongación por Av. Alvear las que organizan el conjunto. Para las CC, por su parte, el centro histórico tiene un contrapunto de igual peso en los sectores de Palermo Viejo y Palermo Hollywood ${ }^{13}$, en forma de puntos dispersos que acompañan la mancha que los subyace.

En este sentido, el análisis de los atractivos por categorías asociado a las líneas argumentales, permitió precisar que las diferencias entre el mapa general y los mapas por grupos de actores, están determinadas principalmente en el tipo de atractivos fomentados por unos y otros grupos (Figura 3).

\footnotetext{
12 Estos elementos urbanos son conceptualizados en La Imagen de la Ciudad (Lynch, 1960) como:

- Sendas, conductos por los que transita el observador (calles, senderos, líneas de tránsito, canales, etc).

- Nodos, puntos estratégicos de una ciudad de los que parte o a los que se encamina un observador, principalmente vinculados al concepto de senda ya que suelen desarrollarse en la convergencia de las mismas.

- Hitos o Mojones, son objetos físicos sencillos, exteriores al observador, claves de identidad e incluso de estructura en el recorrido.

${ }^{13}$ Palermo Viejo (también Ilamado Palermo Soho) y Palermo Hollywood son denominaciones vecinales para el área comprendida entre las calles Scalabrini Ortiz, Dorrego, Córdoba y Paraguay, en el barrio de Palermo, cuyos cambios de patrones de consumo y consolidación de nuevos grupos sociales se ha constatado desde principios de la década de los '90 (Álvarez de Celis, 2003).
} 

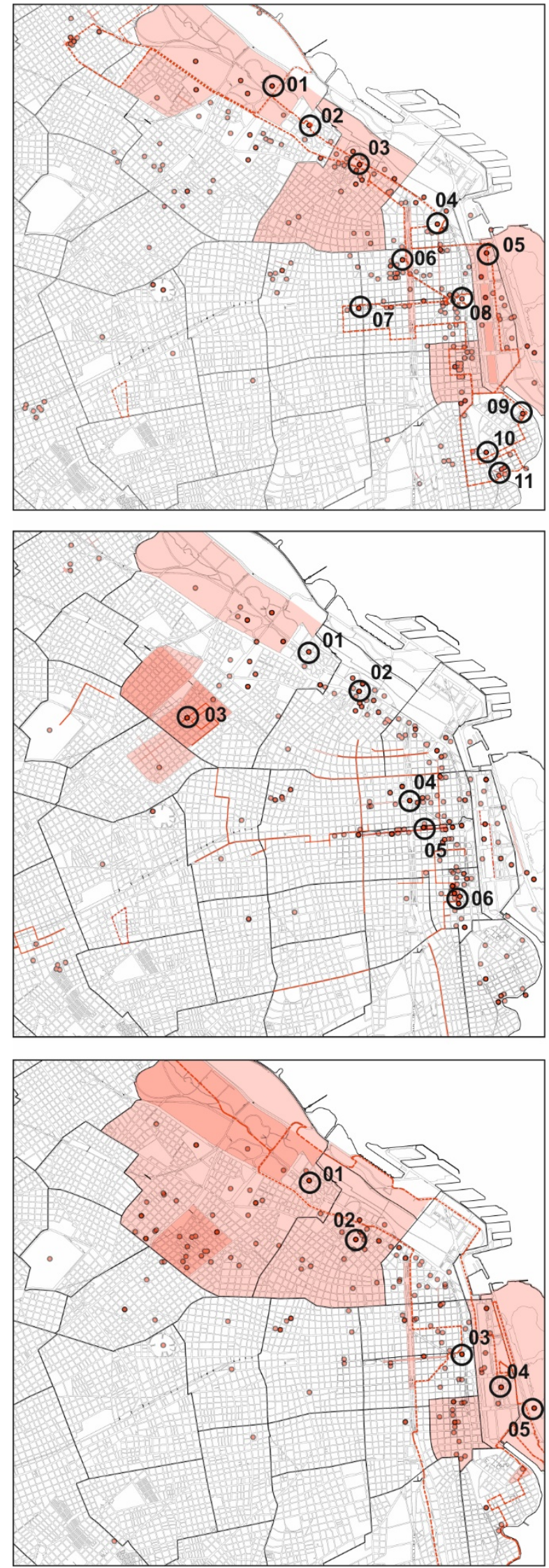

\section{GOBIERNO DE LA CIUDAD}

01. Planetario

02. Museo de Arte

Latinoamericano de Buenos Aires (MALBA)

03. Museo Nacional de Bellas Artes

04. Plaza San Martín

05. Colección de Arte Amalia

Lacroze de Fortabat

06. Teatro Colón

07. Congreso de la Nación

08. Casa Rosada

09. Usina del Arte

10. Estadio Boca Juniors

11. Pasaje Caminito

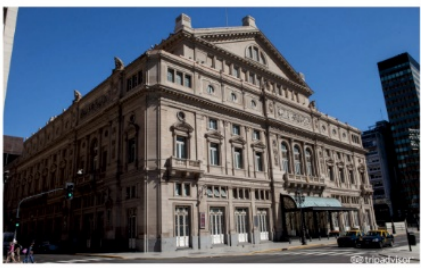

Teatro Colón

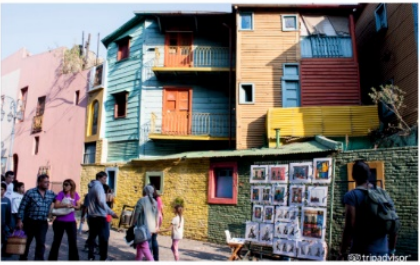

Pasaje Caminito

\section{SECTOR PRIVADO}

01. Museo de Arte

Latinoamericano de Buenos Aires (MALBA)

02. Museo Nacional de Bellas

Artes

03. Plaza Julio Cortázar (Serrano) 04. Obelisco

05. Café Tortoni

06. Mercado de San Telmo y Plaza Dorrego

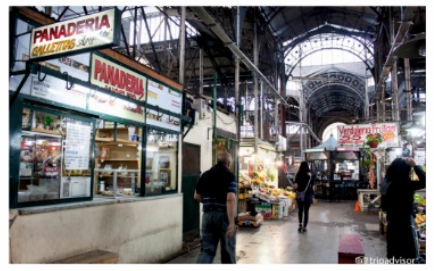

Mercado de San Telmo

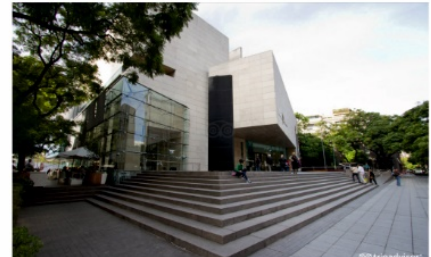

Museo de Arte Latinoamericano de Buenos Aires (MALBA)

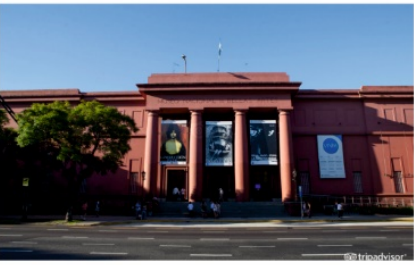

Museo Nacional de Bellas Artes

\section{COMUNIDADES DE CONTENIDO}

01. Museo de Arte

Latinoamericano de Buenos Aires (MALBA)

02. Cementerio de la Recoleta

03. Casa Rosada

04. Faena Hotel

05. Reserva Ecológica Costanera Su

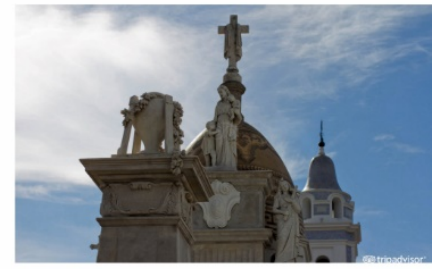

Cementerio de la Recoleta

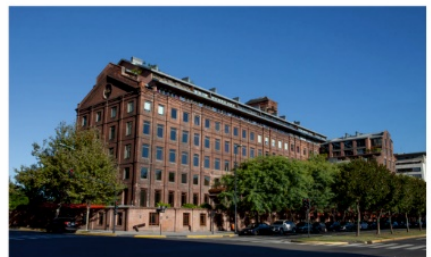

Faena Hotel

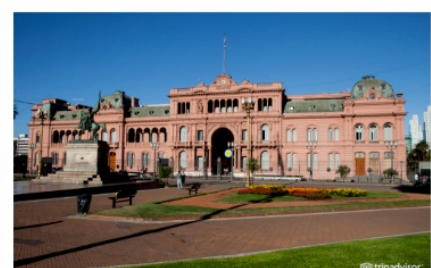

Casa Rosada

Figura 3. Localización espacial de los atractivos y detalle de los más mencionados, según grupo de actores Fuente esquemas: Elaboración propia a partir de los datos recogidos de guías turísticas y comunidades de contenido. Fuente fotografías: Trip Advisor (s.f.) 

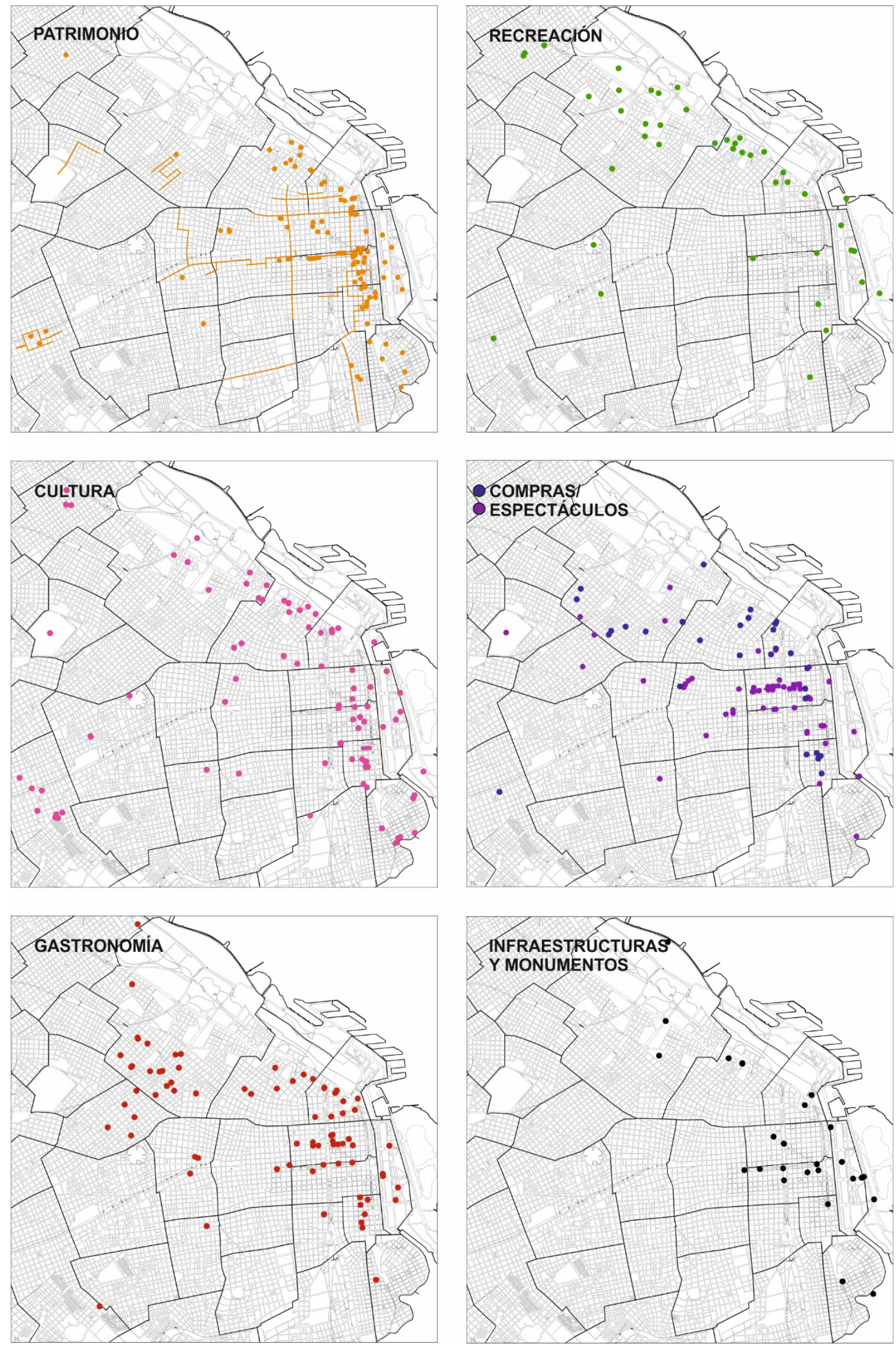

Figura 4. Localización espacial de los atractivos según rubro Fuente: Elaboración propia a partir de los datos recogidos de guías turísticas y comunidades de contenido. 
En primer lugar, la categoría gastronomía, si bien es considerada como una actividad indirectamente vinculada al turismo de acuerdo a la Ley Nacional de Turismo de Argentina (2004), aparece como la segunda más mencionada en las guías. Esta situación responde a una coyuntura de carácter internacional, ya que cada vez más, los destinos están incrementando el uso de la comida como un medio para diferenciarse y expandir su mercado, considerándola como una de las componentes esenciales de la experiencia turística (McKercher, Okumus \& Okumus, 2008). En relación a la distribución espacial de los puntos gastronómicos, podemos constatar que los sectores de Palermo Viejo y Palermo Hollywood son los que concentran la mayor cantidad, lo que parece reforzar la idea de Palermo como polo gastronómico actual.

Sin embargo, son las CC las que con mayor frecuencia hacen mención a este rubro, considerado como una atracción en sí misma, bajo argumentos como "Restaurantes" (Lonely Planet, 2016), mientras que sólo figura como anexo en las guías del GC y SP, a excepción de "Buenos Aires para saborear", en la guía Ciudades a Pie Buenos Aires (2016).

Así mismo, el barrio de Palermo es el que más ítems de recreación concentra, muy por encima de los demás barrios, principalmente por la mención a los Bosque de Palermo y todos los elementos que allí se reúnen: Planetario, Rosedal, Jardín Japonés, etc., bajo argumentos como "Naturaleza y Parques" o simplemente "Bosques de Palermo". Puerto Madero le sigue en número debido a la frecuente mención a la Reserva Ecológica Costanera Sur. Son las guías del GC y SP las que más mención hacen a estos espacios.

Por su parte, la categoría patrimonio construido es la que más puntos concentra, localizados principalmente en el barrio de Monserrat, es decir, en el centro histórico de la ciudad, al igual que la categoría de monumentos/ infraestructura, aunque con menor mención. Es de remarcar para este barrio, como los argumentos bajo los cuales se nombra, tienden a desglosarlo en sub-sectores, lo que da cuenta de la identidad particular que poseen, al tiempo que determinan recorridos preestablecidos que se repiten de una a otra guía: Plaza de Mayo, Av. de Mayo, Congreso o Casco Histórico, se nombran como entidades independientes aunque interrelacionadas; al tiempo que se presenta a Plaza de Mayo como un nodo que articula dos recorridos principales: el de Av. de Mayo uniendo a la Casa Rosada con el Congreso, y el de calle Defensa, partiendo de Plaza de Mayo a Plaza Dorrego.

Existen, también, otros recorridos consagrados que unen puntos patrimoniales por fuera de Monserrat, como el que une a Retiro con Recoleta (el segundo barrio con la mayor concentración de elementos patrimoniales) a través de la Av. Del Libertador y Av. Alvear, o el de 9 de Julio partiendo del Obelisco hasta su cruce con Av. del Libertador. Cabe mencionar en este sentido, la guía "Buenos Aires Cultural" (2016) del SP basada en circuitos patrimoniales por fuera de los habituales, remarcando que son muchos los barrios de Buenos Aires que cuentan con este tipo de atractivos (Villa del Parque, Villa Devoto, Almagro, entre otros) y señalando que incluso existen otros atractivos a mencionar en barrio consagrados, aunque no sean considerados por las otras guías.

La categoría cultura, por su parte, es la segunda más mencionada principalmente en referencia a los museos. De hecho, guías pertenecientes a los tres grupos de actores hacen mención a ellos a través de diferentes nombres: "Buenos Aires y sus museos", "Buenos Aires multicultural" o, simplemente, "Museos". El barrio de Palermo también lidera la concentración de estos ítems, seguido por el barrio de Recoleta. Esta categoría, conjuntamente a la de patrimonio y monumentos e infraestructura, son especialmente mencionadas por GC y SP, y muy por debajo en las CC.

Los dos temas restantes, espectáculos y compras, son introducidos por las CC, teniendo escasa mención en las guías del GC y SP. En relación a los espectáculos, aunque en general tienen más mención los shows de tango, lo cierto es que su distribución dispersa en distintos sectores de la ciudad, conduce a que el barrio de San Nicolás concentre la mayor cantidad de puntos, principalmente asociados a los shows de calle Corrientes. Para el tema compras, el barrio más mencionado es San Telmo, específicamente en relación a la feria de la Plaza Dorrego, el Mercado de San Telmo y a los anticuarios de la calle Defensa. Son mencionadas con frecuencia además, Las Galerías Pacífico de calle Florida, aunque más por su carácter patrimonial que de compras.

Finalmente, otro aspecto a destacar, es el de la incorporación de nuevos barrios al repertorio turístico, especialmente desde las guías del GC, por ejemplo, a través del itinerario "Buenos Aires de los porteños" (Guía de Buenos Aires, 2016) que menciona a los barrios de Barracas, Caballito, Flores y Belgrano. Aunque este último ya es difundido en las guías del SP y CC, por la presencia del "Barrio Chino", las Barrancas de 
Belgrano y el nodo Juramento- Cabildo con la iglesia "La Redonda"14, la incorporación de los otros barrios es más incipiente, sólo mencionados en otras guías por la Av. Montes de Oca, el recientemente activado Tranvía Histórico o en relación al "circuito papal", respectivamente.

\section{REFLEXIONES FINALES}

De manera preliminar, la información analizada en las guías de turismo de Buenos Aires, arroja que la selección de lo que "debe ser visto" y, en este sentido, la noción de atractividad, varía según el grupo de actores que la realiza. En general, parecen existir dos maneras de concebir y mostrar los atractivos en la ciudad, reflejados en los argumentos y en los mapas de localización de las guías, aunque estas no siempre coinciden a nivel discursivo.

La primera, es aquella que desarrollan las guías del GC y SP en los sectores tradicionales: la ciudad europea, la de los inmigrantes y el centro histórico, a través de itinerarios con tiempos precisos, que se repiten en diferentes guías, y que exaltan recorridos uniendo elementos pertenecientes a la esfera del patrimonio construido, a través de ejes de circulación populares. Estos itinerarios, se argumentan de acuerdo al nombre del sector donde se desarrollan o bajo descripciones relativas al imaginario colectivo como "la ciudad elegante", "la ciudad tanguera" o "la ciudad histórica". A su vez, aparece como característica de esta forma de mostrar la ciudad, una multiplicidad de itinerarios que comparten los mismos atractivos, aunque nombrados bajo distintas temáticas, especialmente los que se desarrollan en el centro histórico. Esto podría estar sugiriendo una tendencia ya presente en otras ciudades, la de la especialización y la reducción de los tiempos de recorrido, tal como ya se estudió para la ciudad de Barcelona: "La reducción en los tiempos de los procesos, tanto comunicativos como de producción, también han incidido en los tiempos del turismo en la ciudad. Lo que antes se proponía ver de una sola vez, ahora se subdivide en un montón de fragmentos, acortando los tiempos de recorrido, al mismo tiempo que se tiende a su especialización." (Rodríguez, 2014, p. 61)

La segunda forma, emparentada a las CC, se presenta como opuesta a los itinerarios tradicionales, ya que no determina los atractivos en función de áreas geográficas, sino de categorías que agrupan puntos dispersos en la ciudad, incorporando las actividades de gastronomía, espectáculos y compras, con mayor relevancia que en las guías del GC y SP. Así, contrariamente a la idea de itinerario, generan distribuciones libres, no pautados por el tiempo, aunque determinadas por la relevancia que le otorgan las críticas de los usuarios de dichas webs.

Por otro lado, el discurso generado por el Gobierno de la Ciudad para promocionar a Buenos Aires, se caracteriza por fomentar un turismo especializado o de nichos, a través de la oferta de múltiples "tipos de turismo" que atienden a diferentes públicos e intereses (corporativos, gastronómicos, LGBT, deportivos, etc.) y por la fuerte apuesta a las plataformas digitales como recurso para medir aquellos atributos valorados positivamente por los visitantes. Ambas acciones, tal como lo expresa su página oficial, tienen por objetivo atraer un mayor número de turistas, lo que pone de manifiesto una mirada principalmente económica sobre este tema. Cabe preguntarse, entre otras cuestiones, si el tipo de atractivos que promocionan estos discursos, no conducen al desarrollo de relatos creados ex profeso, como el caso del circuito papal, que aprovecha la elección al papado de Jorge Mario Bergoglio para "poner en el mapa" al barrio de Flores dónde él creció. En este sentido, la teatralización de los escenarios urbanos que menciona García Vázquez (2008) podría ser uno de los riesgos más tangibles, como ya ocurrió, por ejemplo, en el pasaje Caminito del Barrio de La Boca.

Al mismo tiempo, siguiendo ese lineamiento discursivo, las intervenciones de CCCA desarrolladas por CAME en los cascos históricos de diferentes ciudades del país, e incluso en Capital Federal, se proponen fomentar la competitividad del comercio de calle a través de acciones de renovación urbana y de promoción comercial, abogando a su rescate identitario. Sin embargo, como se ha constatado en el trabajo en curso, ${ }^{15}$ en escasas intervenciones se especifica cuál es la identidad que quiere rescatarse, como tampoco parecen tenerse en cuenta las particularidades comerciales de cada sector al momento de proponer las acciones de renovación. Algo que podría aplicarse también a los nuevos proyectos urbanos impulsados por el Gobierno de la Ciudad respaldadas por las ideas de innovación y la de crear una "ciudad cosmopolita", como el caso del "Parque de

\footnotetext{
${ }^{14} \mathrm{La}$ integración de este barrio al repertorio aparece como una continuación natural del recorrido consolidado para sector norte, que ya contando con Retiro, Recoleta y la zona de los bosques de Palermo, en los últimos diez años incorporó al "otro" Palermo, o lo que La Guía de Buenos Aires (2016) llama "el Buenos Aires de Autor". Un caso a destacar en este sentido es el del Bus Turístico, que hasta el año pasado (2016) contaba, con dos recorridos, que a principios de 2017 se dividieron en tres, incorporando el sector lindante a Palermo Viejo o Soho, lo que también acusa el creciente interés en el sector.

${ }^{15}$ Ver (Vecslir \& Rodríguez, 2017).
} 
la Innovación" en el actual Tiro Federal contiguo al barrio de Belgrano, el "Distrito Joven" en Aeroparque en el barrio de Palermo o el "Shopping de Caballito" en el barrio de Caballito ${ }^{16}$.

Desde las CC, por otro lado, se listan actividades que ofrecen acercar al turista a lo "intrínsecamente porteño", lo que muchas veces conduce a señalar atractivos por fuera de los circuitos tradicionales. Sin embargo, muchos de estos atractivos se desarrollan en el marco de ambientes familiares y hasta de una sofisticación ajena a su tradición. Por caso, a través del énfasis puesto en la de la gastronomía de Palermo Viejo y Palermo Hollywood, que está conduciendo a la incorporación de estos sectores a los circuitos promocionales, aunque las comidas que allí se comercializan se alejan de lo típicamente porteño o argentino, aproximándose más a un producto estandarizado ${ }^{17}$. Cabe preguntarnos, en este sentido, si los rankings bajo los que las CC postulan los atractivos, no conducen a la perpetuación de los mismos atractivos e itinerarios, debido a la retroalimentación que las críticas y comentarios on-line suponen y, en relación a ello, si la búsqueda de "lo auténtico" por parte de los turistas, con la consecuente colonización de sitios que escapaban al paisaje turístico, no conduce a su inexorable masificación.

Sin dudas, el análisis del paisaje turístico de las ciudades es complejo, principalmente dada la diversidad de intereses y actores involucrados en su construcción. Este trabajo intentó evidenciar cuáles son los atractivos que ciertos actores seleccionan para la construcción de dicho paisaje, en las guías de turismo, sin ignorar que esas selecciones son producto del contexto económico, político, social, cultural, etc. de quienes las desarrollan, y sin desconocer tampoco, que son producto de un devenir histórico, aunque su estudio escape a los límites de la presente ponencia. Sin embargo, aunque inconclusa, esta primera aproximación al paisaje turístico ya genera nuevos interrogantes que pueden derivar en otros ejes de debate y estudio: ¿cuál es el impacto de estas selecciones en la ciudad construida y en la vida de sus habitantes? ¿Cómo afectan estas selecciones a la identidad socio- espacial tradicional de los lugares promocionados aquella que, en muchos casos, los popularizó en primer lugar? El trabajo continúa.

\section{BILBIOGRAFÍA}

ÁLVAREZ DE CELIS, F. (2003). Transformaciones económico-territoriales en las áreas de Palermo Viejo y Palermo Hollywood. Cuadernos de Trabajo 5, Centro de Estudios para el Desarrollo Económico Metropolitano (CEDEM).

BAUDRILLARD, J. (1993). El intercambio simbólico y la muerte. Caracas: Monte Ávila.

BERTONCELLO, R. y TRONCOSO, C.(2014). La ciudad como objeto de deseo turístico: renovación urbana, cultura y turismo en Buenos Aires y Salta (Argentina). Gran Tour: revista de investigaciones turísticas(9), 426.

COHEN, E. (2005). Principales tendencias en el turismo contemporáneo. Política y Sociedad, 42, 11-24.

CORBOZ, A. (2004). El territorio como palimpsesto. En Á. Ramos, \& S. d. Universitat Politècnica de Catalunya (Ed.), Lo urbano en 20 autores contemporáneos (págs. 25-34). Barcelona.

COSGROVE, D. (1985). Prospect, Perspective and Evolution of the Landscape Idea. Transactions of the Institute of British Geographers, 10(1), 45-62.

DUNCAN, J. (1995). Landscape geography, 1993-94. Progress in Human Geography, 19(3), 414-422.

FLORIDA, R. (2002). The rise of creative class. New York: Basic Books.

GARCÍA VÁZQUEZ, C. (2008). Ciudad Hojaldre: visiones urbanas del siglo XXI. Barcelona: Gustavo Gili.

GOBIERNO DE LA CIUDAD DE BUENOS AIRES. (2016). Guía de Buenos Aires. (s.I).

HIBU S.A. (Ed.). (2015). Viajar Hoy. Guía Turística Argentina. Ciudad Autónoma de Buenos Aires: IPESA.

16 Ver "Rodríguez Larreta juega su futuro político a una alianza con los inversores inmobiliarios" en: http://www.perfil.com/politica/rodriguez-larreta-juega-su-futuro-politico-a-una-alianza-con-los-inversores-inmobiliarios.phtml.

17 Ver Rodríguez (2016). 
JUDD, D. (2003). El turismo urbano y la geografía de la ciudad. Eure, 29(87), 51-62.

KAPLAN, A. y HAENLEIN, M. (2010). Users of the world, unite! The challenges and opportunities of Social Media. Business Horizons(53), 59-68.

LACARRIEU, M. (2013). Entre el lugar antropológico y el lugar disputado: hacia una antropología del lugar. Sociedade e Cultura, 16(1), 15-26.

LYNCH, K. (1960). La imagen de la ciudad. Barcelona: Gustavo Gili.

MACCANNELL, D. (1999). The Tourist: A New Theory of the Leisure Class. New York: Schocken.

MATTOS, C. (2010). Globalización y metamorfosis en América Latina. hacia una nueva forma urbana. Quito: Colección textos Urbanos $n^{\circ} 4$.

MCKERCHER, B., OKUMUS, F. y OKUMUS, B. (2008). Food Tourism as a Viable Market Segment: It's All How You Cook the Numbers! Journal of Travel \& Tourism Marketing, 25(2), 137-148.

MINISTERIO DE JUSTICIA Y DERECHOS HUMANOS, PRESIDENCIA DE LA NACIÓN (2004). Ley Nacional de Turismo. Ciudad Autónoma de Buenos Aires.

ORGANIZACIÓN MUNDIAL DEL TURISMO. (2011). Tourism Towards 2030 / Global Overview. Madrid: UNWTO.

ORGANIZACIÓN MUNDIAL DEL TURISMO. (2017). Panorama OMT del turismo internacional. Edición 2016. Madrid: OMT-UNWTO.

PROSDOCIMI, A. (Ed). (2016). Buenos Aires. Ciudades a Pie. Ciudad Autónoma de Buenos Aires: Arte Gráfico Editorial Argentino.

RAMIREZ, L. (2008). Turismo, naturaleza y territorio: el turismo termal en la localidad de Federación (Tesis de Maestría). Mar del Plata: Universidad Nacional de Mar del Plata.

RITZER, G. y JURGENSON, N. (2010). Production, Consumption, Prosumption: The nature of capitalism in the age of the digital 'prosumer'. Journal of Consumer Culture, 10(1), 13-36. doi:10.1177/1469540509354673

RODRíGUEZ, L. (2016) Paisaje Turístico y Gastronomía en Palermo Viejo. 9th International Conference of the International Forum on Urbanism (IFoU): From Knowledge to Development: New University challenges for a contemporary urban development. UBA, FADU Buenos Aires 2016.

RODRÍGUEZ, L. (2014) Excursión Barcelona: itinerarios a través de la ciudad. (Tesis de Maestría) ETSAB, Universidad Politécnica de Cataluña. Barcelona.

SOPER, A., GREER, C., METRO-ROLAND, M. y KNUDSEN, D. (Edits.). (2008). Landscape, tourism and meaning. Indiana University, Bloomington: Ashgate Publishing Ltd.

TRONCOSO, C. (2013). La estetización de la Quebrada de Humahuaca (Jujuy, Argentina): Turismo, patrimonio y adecuaciones del lugar para el consumo turístico. Ería(91), Ería.

URRY, J. (1990). The tourist gaze: leisure and travel in contemporary societies. Londres: Sage Publications.

VECSLIR, L. y RODRÍGUEZ, L. (2017). Centros Comerciales a Cielo Abierto y Restructuración de las Centralidades Tradicionales en el Conurbano Bonaerense. Trabajo presentado al $3^{\circ}$ Congreso Internacional de Estudios Urbanos a realizarse del 4 al 6 de Abril de 2017.

ZUKIN, S., LINDEMAN, S. y HURSON, L. (2015). The omnivore's neighborhood? Online restaurant reviews, race, and gentrification. Journal of Consumer Culture, $0(0), 1-21$. 


\section{Fuentes electrónicas:}

ASOCIACIÓN ART NOVEAU DE BUENOS AIRES. (2016). El gran mapa del Art Noveau porteño. Recuperado de <http://www.aanba.com.ar/mapas-y-tours/el-gran-mapa.html> (Consulta: 20/10/2016)

BUENOS AIRES BUS. (2016). Recorrido. Recuperado de <http://www.buenosairesbus.com/faq.html> (Consulta: 06/03/2017)

CÁMARA ARGENTINA DE LA MEDIANA EMPRESA. (2016). X Seminario Internacional de Centros Comerciales a Cierlo Abierto. Recuperado de <http://www.redcame.org.ar/contenidos/circular/X-Seminario Internacional-de-Centros-Comerciales-a-Cielo-Abierto_-_br_-Cronica-del-encuentro.6894.html> (Consulta: 26/01/2017)

CLARÍN. (2016). Buenos Aires, la preferida de Sudamérica. Recuperado de $<$ http://www.clarin.com/ciudades/ciudad_de_buenos_aires-ranking-tripadvisorsudamerica_0_By1e2HR_Dml.html> (Consulta: 26 de Enero de 2017)

INSTITUTO DE PROMOCIÓN TURÍSTICA INPROTUR (s.f.). Marca País. Recuperado de <http://www.turismo.gov.ar/inprotur> (Consulta: 21/10/2016)

LONELY PLANET BUENOS AIRES. (s.f.). Recuperado de <https://www.lonelyplanet.com/argentina/buenosaires> (Consulta: 29/08/2016)

ORGANIZACIÓN MUNDIAL DE TURISMO. (s.f.) Entender el turismo: Glosario Básico. Recuperado de <http://media.unwto.org/es/content/entender-el-turismo-glosario-basico> (Consulta: 28/04/2017)

PERFIL, PERIODISMO PURO. (2016). Rodríguez Larreta juega su futuro político a una alianza con los inversores inmobiliarios. Recuperado de <http://www.perfil.com/politica/rodriguez-larreta-juega-su-futuropolitico-a-una-alianza-con-los-inversores-inmobiliarios.phtml> (Consulta: 3/03/2017)

SLIDESHARE. (2016). Plan Federal de Turismo 2016. Recuperado de <http://www.slideshare.net/CamaraArgentinadeTurismo/plan-federal-de-turismo-2016-mintur-argentina> (Consulta: 21/10/2016)

SITIO OFICIAL DE TURISMO DEL GOBIERNO DE LA CIUDAD. (2016). Buenos Aires, la ciudad más interactiva de Latinoamérica. Recuperado de <https://turismo.buenosaires.gob.ar/es/article/noticia-buenosaires-la-ciudad-m\%C3\%A1s-interactiva-de-latinoam\%C3\%A9rica> (Consulta: 24/01/2017)

SITIO OFICIAL DE TURISMO DEL GOBIERNO DE LA CIUDAD. (s.f.). ¿24 $h$, 48h o una semana? Recuperado de <https://turismo.buenosaires.gob.ar/es/agrupador-noticias/\%C2\%BF24-h-48-h-o-una-semana> (Consulta: 24/01/2017)

TIME OUT. (s.f.). 20 great things to do in Buenos Aires. Recuperado de <http://www.timeout.com/buenosaires/features/50/20-great-things-to-do-in-buenos-aires> (Consulta: 16/09/2016)

TRIP ADVISOR. (s.f.) Barrios de Buenos Aires [Figura 3] Recuperado de: <https://www.tripadvisor.com.ar/NeighborhoodList-g312741-Buenos_Aires_Capital_Federal_District.html> (Consulta: 25/04/2017)

TRIP ADVISOR. (s.f.). Atracciones en Buenos Aires. Obtenido de <https://www.tripadvisor.com.ar/Attractionsg312741-Activities-Buenos_Aires_Capital_Federal_District.html> (Consulta: 12/09/2016)

TRIPADVISOR. (2013). About Trip Advisor. Recuperado de <https://www.tripadvisor.co.uk/PressCenteri6603-c1-Press_Releases.html> (Consulta: 13/10/2016)

TRIP ADVISOR. (s.f.). Fact Sheet. Recuperado de <https://www.tripadvisor.com/PressCenter-c4 Fact_Sheet.html> (Consulta: 13/10/2016) 